\title{
遠心圧縮機入口部における逆流を伴う流れ場の可視化
} 荒巻森一朗，阪本 崇介”, 舩越 康宏 (九州大学)，速水 洋

\section{Visualization of Inlet Flow Fields with Reverse Flow of a Centrifugal Compressor}

Shinichiro ARAMAKI, Shusuke SAKAMOTO, Yasuhiro FUNAKOSHI and Hiroshi HAYAMI

\section{ABSTRACT}

The operating range of a centrifugal compressor is usually limited by the choke and the surge. The surge is related to the compressor system but it deeply relates to the inlet stall of impeller and/or the diffuser stall. Therefore, the velocities of three types of flow rates were measured velocity distributions using a PIV at the three sections in impeller inlet. The correlations between the swirl flow and the reverse flow in the impeller inlet were discussed using $3 \mathrm{C}$ velocity distribution of a stereoscopic PIV system.

Keywords : Dynamic PIV, Centrifugal compressor, Stall

\section{1. 精 諭}

遠心圧維機の運転限界小流浢は，通常，羽根車やディ フューザによる失速を原因としたサージ現象により制限

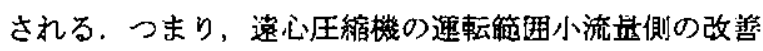
には一部の翼に生じる失速を挪制することが必要である。 既報ではダイナミックステレオPIV"を用い，6,000rpm 厄゙回転する邀心压箱機の羽根車人口部断面において，主

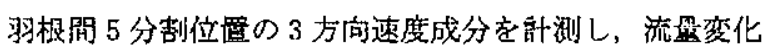
に上万面外方向速度分布と画内周方向速度分布の成逨性 を示した．本報では，3万向速度部測断面にお打る速庭

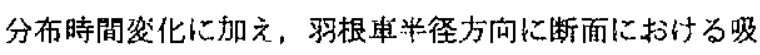
い込み流れ速庭分布，および羽根本人口上流部における 周方向速度の存在確認を目的とした計測断面を追加し， 羽根車入口断面の3 速度分布と併せることで，三次元流 れ楧造の解明を試みた。

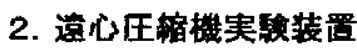

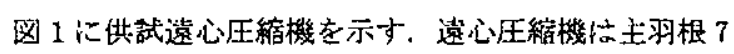
枚の中間羽根付羽根莗とバーンレスディフューザで構成 される. 羽根本の入山画径は $72 \mathrm{~mm}, 4$ 仙直径は $98 \mathrm{~mm}$ である. 羽根本の回転数仕 $8,000 \mathrm{rpm}$ 一定とした。图
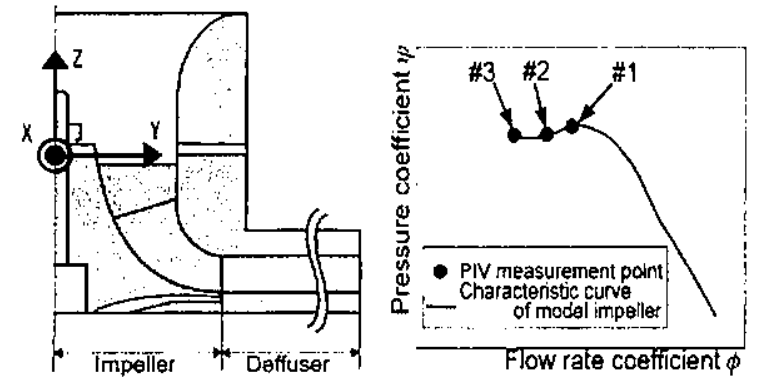

Fig.1 Test compressor and characteristic curve.

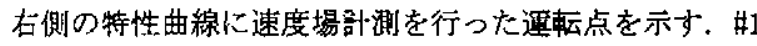
は安定连湳点，\#2 は羽柀車入口壁面静压に変動のある 不安定運転点，\#3 は完全失速点である.これらの暂転 状態および連転条件は，回転数に加え，弁開度，入口お 上び出口部壁面觧压，出口流量および空筑温度により監 視を行った。

\section{3. 実験方法と㖕鸿システム}

羽根車入口部速度分布を確認寸るために 3 種類のPIY

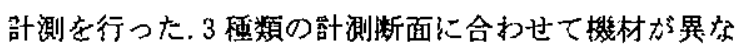
るが，PIVに必要なトレーサ精子は共通であり，粒子発

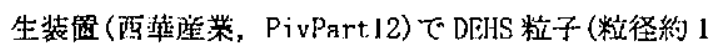
$\mu \mathrm{m})$ を用いた。咶測 3 断面を，图 1 左に示す $\mathrm{x}, \mathrm{y}, z$ の 各方向を用いて $\mathrm{x}-\mathrm{y}$ 人口断面, $\mathrm{y}-\mathrm{z}$ 子午面， $\mathrm{x}$-2 弦断面 とし，以下に辞細を説明する。

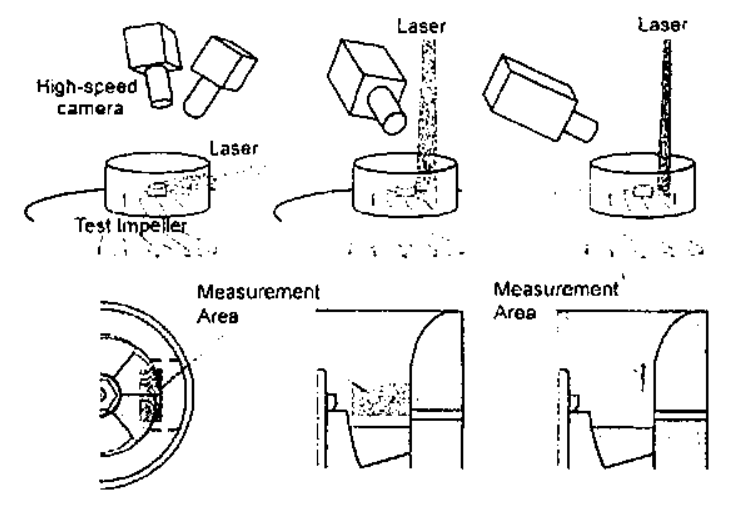
(a) $x-y$ section
(b) $y-z$ section
(c) $x-z$ section

Fig.2 Experimental apparatus and measurement area(three sections). 


\section{$3.1 \mathrm{x}-\mathrm{y}$ 入口断面竍㳔}

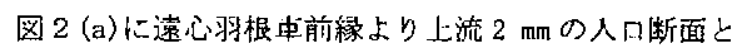

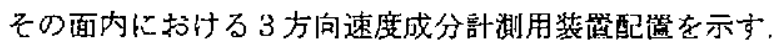
ダイナミックステレオPIVとして2台り宫速度カメラ

(Photron, FASTCAM MAX)を羽根車入口上流部に入テレ我 配置した，照明は漓䆆り返し YLF レー少” (Coherent, Evolution30 DPO，527nm，23mJ(1kHz) および光学系二 ニットで $2 \mathrm{~mm}$ 厚のレーザシートにより行った．羽根車

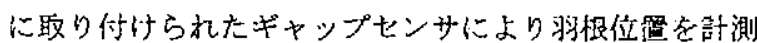
L, 分)洁信岁発生器 (小野測器, CF-070 Order Analysis Unit)で主羽根間を 4 等分割した信号を発生させた。 こ の信号を元にデジタル遅延信号発生器(BNC, Mode1565) でカメラとレーザを同期させ，タイナミックPIV 計浿を

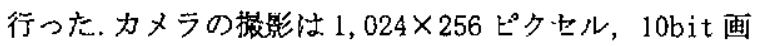
像を毎秒 7,467 フレ一ムで行った.2 台のカメラのなす 角は20度であり，それぞれののカメラとレンズ(Nikkor

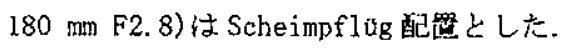

\section{$3.2 \mathrm{y}-\mathrm{z}$ 子午面計测}

図2 (b)に羽根車回伝中心を通る下午消位置上軸流方

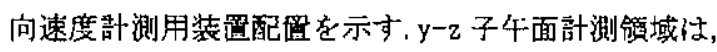
下端が羽根車入日上り上流 $2 \mathrm{~mm}$ ，上端が $15 \mathrm{~mm}$ となる。 高速度カメラ(Photron，FASTCAM SA1.1)で $512 \times 512 と 0$ クセル，12bit 画像を篮秒 20,000 フレームで报影索行 った. 照明は, 半導体励起CWレーザ(エムスクェア製, 2W，532n(m)で，上流部よりシート厘 $2 \mathrm{~mm}$ で行った。計測 面に対し正面からの錐影ではケッシ・ンダによるケラレが 発生するため，斜为位首から揖影を行った。

\section{$3.3 x-2$ 弦断面計湖}

图 2 (c) に羽樶東半径比 0.9 の弦を含む $\mathrm{x}-\mathrm{z}$ 弦断面と

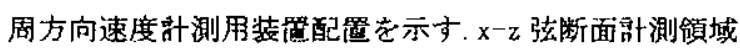
は，下端が羽根車入口より上流 $9 \mathrm{~mm} ，$ 上端が $19 \mathrm{~mm}$ とな 万.中央の半径比忙 0.9 , 两端部は 0.96 である。高速 度カメラ(Photron, FASTCAM SA5)で $512 \times 272$ ピクシル， $12 b i t$ 画像を策秒 50,000 フレ・ムで掫影を行った．照

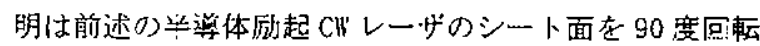
させて使用した， $\mathrm{y}-\mathrm{z}$ 子午面計測同様に回転軸此よるケ ラレ対策として，計测領域を上流側へ移酚し，更に計測 面に対し斜め位视からの撮影を行った。

\section{4. 吱測結果}

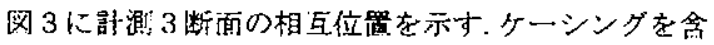

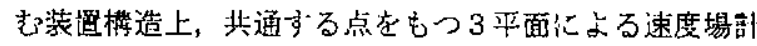
測が困難であったが，図に示す上うな配置とすることで， 检証を行った。

\section{1 流量效化決伴う $x-y$ 入口断面速度分布}

図 4 に $x-y$ 入口踭面訫測で得られた周方向速度 (上段) と面外速度 (下段)の半径方向分布を 10 時刻分 (2. $68 \mathrm{~ms}$ )

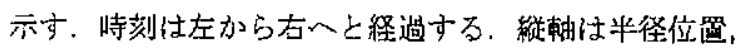

横軸は羽根車外端の周速度で無次元化した速度分布を示 す，羽根車回転方向速度および逆流方向速度の大きな頌 域を筑りつぶした，周方向速度は旋回流を正，面外方向

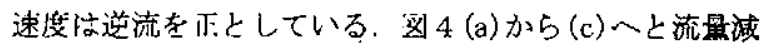
少とともに逆流発生領域の航大が確認できる。逆流速怯 上り外周部の方が大き值を示寸傾向がある，不安定速 転時(b)で注周方向书上び面处方向速度の大きさ㳊時間 変化が見られる. また, (b)では怪比 1.0 近傍, 完令 失速通転時 $(\mathrm{c})$-c性半径比 0.8 以上の領域に扔いて递流 時お上び吸込み流れの確認できる時刻がある。

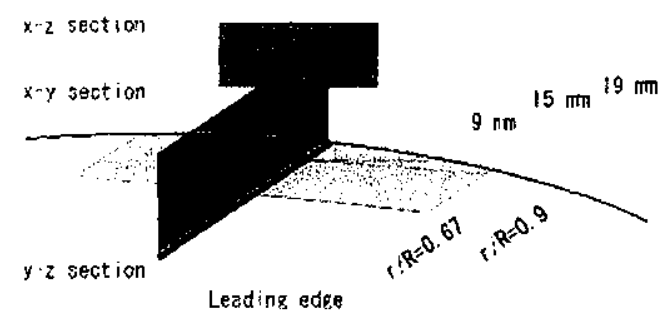

Fig.3 Measurement areas(three sections).

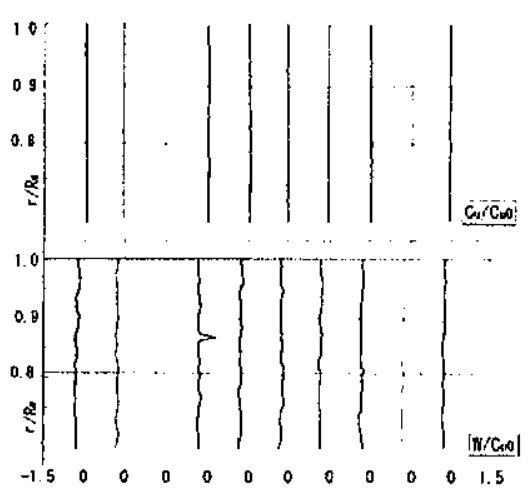

(a) steady flow(\#1)

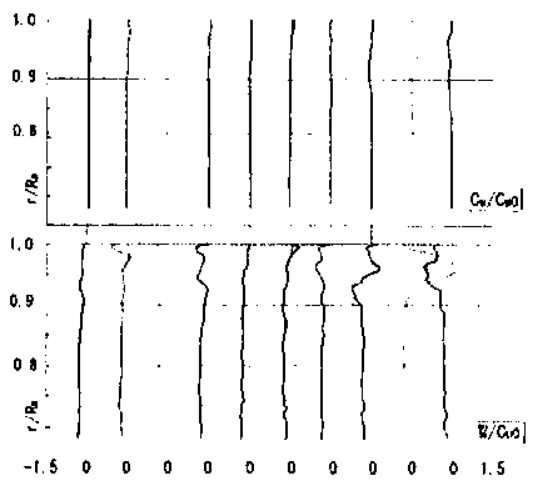

(b) partial unsteady flow (\#2)

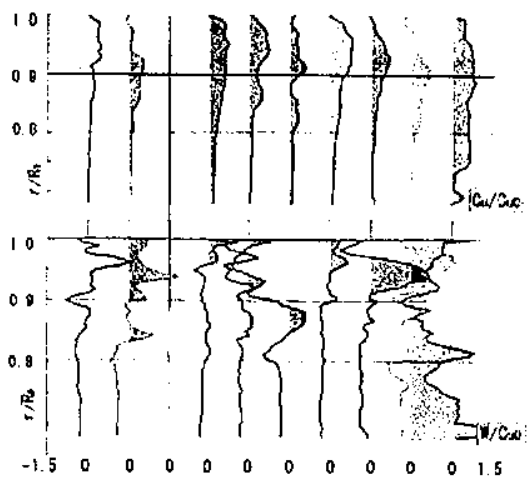

(c) unsteady flow $(\# 3)$

Fig. 4 History of radial distribution of velocity, upper $=$ swirl flow, bottom $=$ axial flow . 


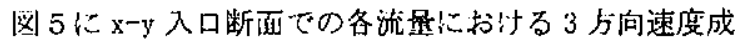

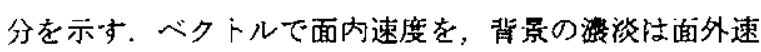
度成分を表方，淡色が順流，䈨色が逆流を示方，图上部

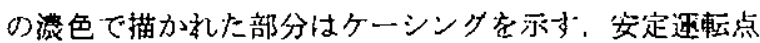
である图 5 (a) で江右侧に背景の羽根解秝の影響がみら れるが，全㓦心おいて暊流の流れ場であり，旋回速度成

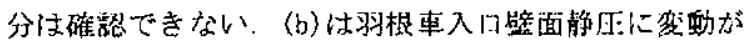
生じる速転点であり，泿色で示方逆流域が存在し，そ0 周辺を含的て旋回速度げ大きくなっている，完全失速状 態である(c)においては外周部に大きな旋回流域が確認 できる，そこで(d)は速度ベクトルの沗示数を減少させ

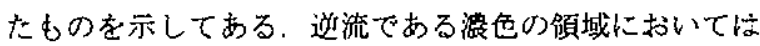
人きな旋回速度成分が礁認できる，また，順流である淡

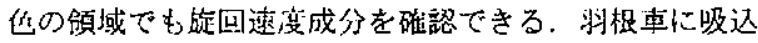
生れる流れは旋回をもたないが、逆流分が再度吸込まれ

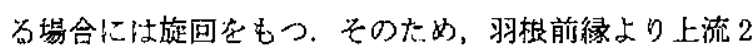
$\mathrm{mm}$ 位瑥において道流域坊よひ順流域に旋回速度成分 犻碓認される。

\section{2 吸込㐬れの半径方向速度分布}

图 6 に $\mathrm{y}^{-\mathrm{z}}$ 子平面における, 各䦽転状態の代表的な速

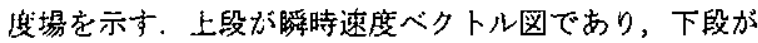
その流楾を示す，各図の左端势半径比 0.33 ，石端が 1.0 である。:の速度計側面において，安定遇転時の主流流 上部から羽根車への予旋回をもたない吸运多流れである。 従って、こけ計测面でベクトルが得られない理由として トレーサ粒子方存在しない場合，買およびターシングの

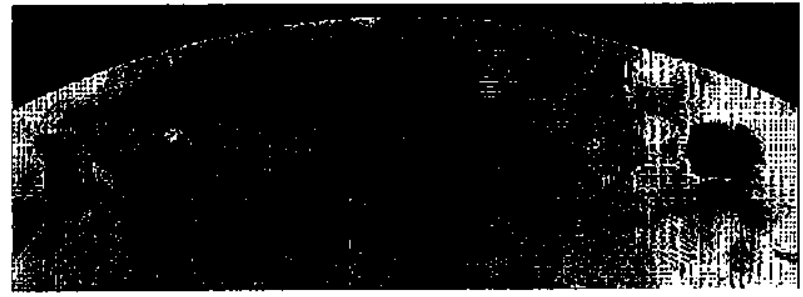

(a) steady flow (\#1)

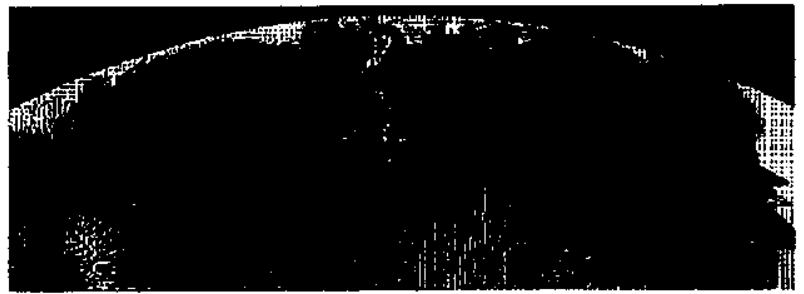

(c) unsteady flow (\#3)

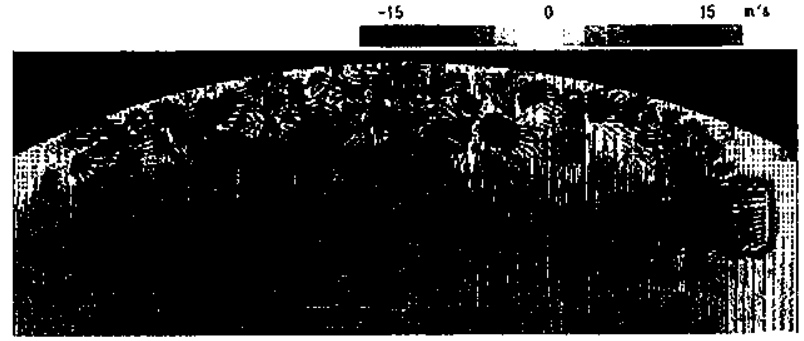

(b) partial unsteady flow (\#2)

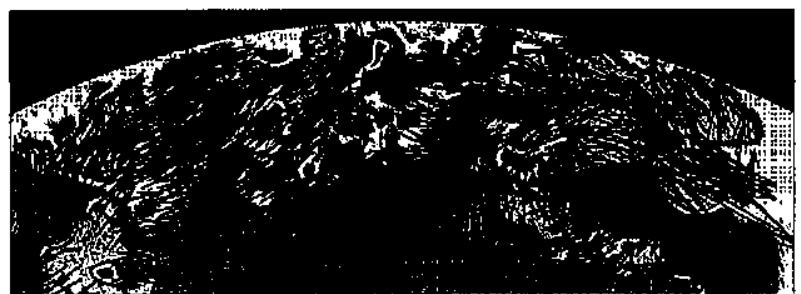

(d) unsteady flow (half Vectors)

Fig.5 Relation between swirl flow vector and reverse flow contour maps.
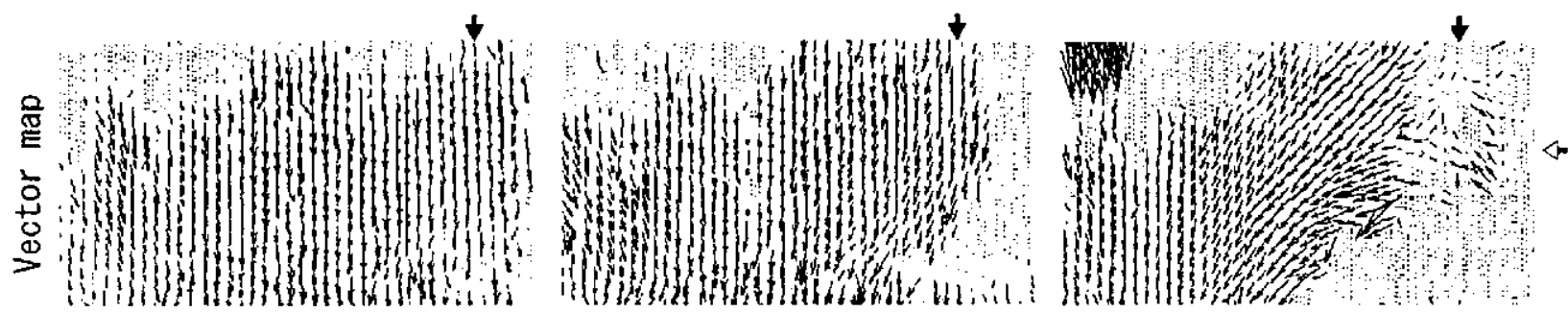

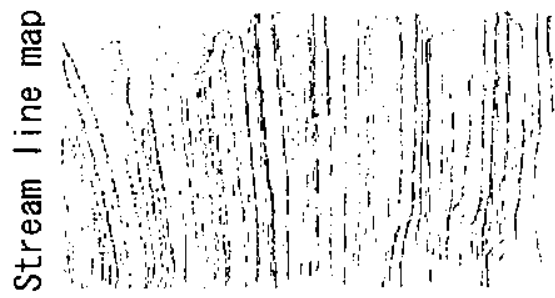

(a) steady flow (\#1)

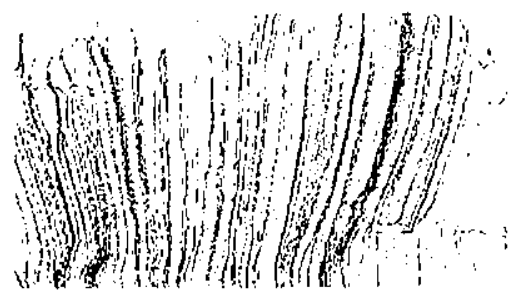

(b) partial unsteady flow( $\# 2)$

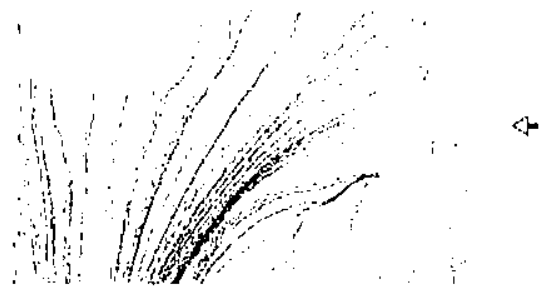

(c) unsteady flow (\#3)

Fig.6 Instantaneous velocity vector and stream line maps of $y-2$ section. 
影幚でトレーサが確諰できない場合，面外速度が大きく PIVの 2 畔面における相関が得られない埸合の3つが举 げられる，安定運轱点である図6(a)では，羽根車の八 ブ側から翼端側までほぼ一様な吸込み流れが確認できる。 不安定连転点(b)も傾向は (a) と同じであるが，翼端部で 吸込み流れが半径内问きへ方向を孪えていることが確態 できる. 更に, 完全失速運転点(c)では，翼端.上流部から 半径比 0.6 近傍灾で半径内问き流れが㩆著である（b)， (c)における臬度べクトルの算出ができなかった領域の 原画像を磪認したこころトレー・州粒子が記録されている

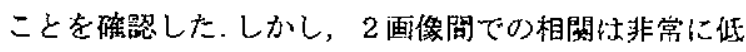
いことを確認した，㮸って，前述の面外速度が大きい，つ まり旋回速度成分の大きな領域であると思われる。そこ で図上部に黒矢印で示す半径比 0.9 にお引る垂直な部測 面 $x-z$ 弦渐面の速度分布例芫以下で检討寸る.

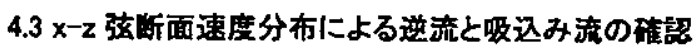

阁 7 に $-\mathrm{z}$ 弦断面の運転状热の遠いに上る瞬時速度ベク トル図を示す，図の下端分图 6 の右に白矢印で示した位 嘈 (羽根前緑より $9 \mathrm{~mm}$ 上流)である.トレ一サ粒子の有無 がそのままべクトル表示数に影響している. 安定運転点

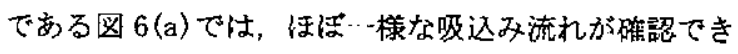
る、不安定運転点である(b)でも傾向济(a)と同じであり， この計測位置における(a)，(b)の明確な差はみられない。 図6(b)においても，白失所の高さ位膡における速度へ クトルは安定した吸込み状態を維持しているためである。 (c)於よび(d)に完全失速点に㧍ける瞬時速度場の例を示 す（c）において，中央で忙垂直方向に吸込み流礼が発 生しているのに対し，端部では複雑な流れ場が存在して

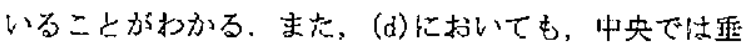
直方向に吸込办流れが発生しているのに対し，右側部で 羽根車回転方向の旋回流が登生していることがわが。

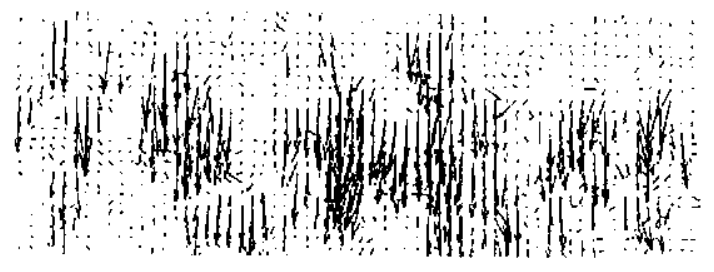

(a) steady flow (\#1)

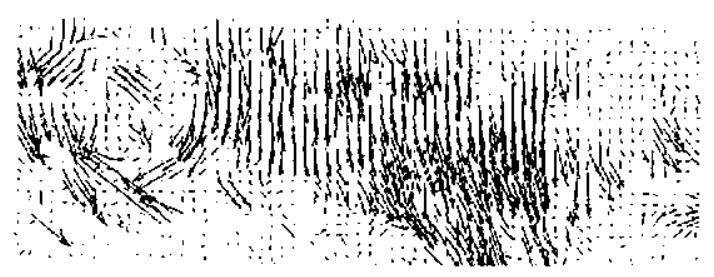

(c) unsteady flow (\#3)
これは，逆流による巽端部からの噴出流が吸込み流れに 影響を与え、この上うな流れ場を形成していると考えら れる。また，雨端で特徵的な流れが確諗できるの仙， 半径比の違い上㖕測西に対方当流れ角の谴い纪よるもの 之考えられる.

\section{5. 結 雫}

遠心死箖橙羽根車の入口部にダイナミックステレオ PIVを道用し，8，000 rpmで回転する羽根車主翼問を 4 分割した 3 速度成分取得した，その結果の梌部材料と して，子午面速度分布および事径比 0.9 を通る弦断面の 速度分存について検討し，流量琙少時に生じる道流と旋 回流発生の関連性索確就した.

\section{参考文献}

1) 荒巻森一朗，速水洋：区繶譏入口失速流九場の可視化测， 可視化伎報，Vol.27，Suppl.No.2 (2007) pp.99-100.

Fig.7 Instantaneous velocity vector maps of $x-z$ section. 